\title{
Study of grape bioactive stilbenes by suspect screening metabolomics
}

\author{
M. De Rosso, L. Bavaresco, F. De Marchi, A. Dalla Vedova, A. Panighel, M. Gardiman and R. Flamini* \\ Consiglio per la Ricerca e la Sperimentazione in Agricoltura, Centro di Ricerca per la Viticoltura (CRA-VIT), \\ Conegliano (TV), Italy
}

\begin{abstract}
Stilbenes are one of the main classes of grape polyphenols associated with the beneficial effects of drinking wine. In the present study, a "suspect screening" metabolomics approach was used to study these grape compounds. Analysis was performed by Ultra High Performance Liquid Chromatography/Quadrupole Time-Of-Flight (UHPLC/QTOF) mass spectrometry and compounds were identified using the database GrapeMetabolomics expressly constructed. By this approach, a total of 18 stilbene derivatives was identified in two V. vinifera red grape varieties (cvs. Raboso Piave and Primitivo) on the basis of accurate mass measurements and isotopic patterns. Identifications were confirmed by multiple mass spectrometry (MS/MS). Bioactive stilbenes such as trans-resveratrol, Z- and E-piceid, piceatannol and Z- and E-astringin, and several resveratrol dimers, trimers and tetramers such as pallidol and pallidol-3-O-glucoside, E- and Z- $\varepsilon$-viniferin, E- and Z- $\delta$-viniferin, caraphenol B, parthenocissin A, E- and Z-miyabenol C, hopheapenol, ampelopsin H, vaticanol C-like or isohopeaphenol, were identified. In our knowledge, some of these resveratrol trimers and tetramers were reported in grape for the first time.
\end{abstract}

\section{Introduction}

Stilbenes are the grape compounds also present in the wine and are one of the main classes of polyphenols associated with the beneficial effects of drinking wine [2]. An epidemiological study carried out in the late 1970s showed that in France, despite the high consumption of food rich in saturated fatty acids, the incidence of mortality from cardiovascular diseases was lower than in other comparable countries. This phenomenon, called the "French paradox", was correlated with the beneficial effects of consuming red wine as a major factor [17].

Resveratrol showed anti-cancer, anti-oxidant and anti-inflammatory activity, confers cardioprotection and inhibits platelet aggregation $[3,7,8,11,12,16]$.

${ }^{*}$ Corresponding author: R. Flamini, Consiglio per la Ricerca e la Sperimentazione in Agricoltura - Centro di Ricerca per la Viticoltura (CRA-VIT), Viale XXVIII aprile 26, 31015 Conegliano (TV), Italy. E-mail: riccardo.flamini@entecra.it.
Piceatannol was reported to block LMP2A (viral protein-tyrosine kinase implicated in leukemia, nonHodgkin's lymphoma and other diseases associated with the Epstein-Barr virus), and to act on human melanoma cells $[9,14,19]$. Viniferins and resveratrol trimers and tetramers are formed by oligomerization of trans-resveratrol in grape tissues as active defense against exogenous attack, or produced by extracellular enzymes released from pathogens in an attempt to eliminate undesirable toxic compounds $[4,18]$.

Metabolomics is the comprehensive qualitative and quantitative study of all the metabolites in a biological system (cell, tissue or organism). In general, 'untargeted metabolomics' provides high sensitivity, good resolution and high-throughput capacity, and in wines can reveal several thousand signals of candidate biomarkers in a single run [1]. Targeted metabolomics is performed for quantitative studies on specific compounds and most of the metabolome information of complex samples, such as wines, is missed [5,21]. Suspect screening analysis is a mid-way approach. This 
method of identification of metabolites relies on the availability of specific information on compounds, e.g., their molecular formula and structure [13].

In the present study, suspect screening metabolomics was used to study stilbenes in two red grape varieties (Raboso Piave and Primitivo). Compounds were characterized by accurate mass spectrometry analysis using a Ultra High Performance Liquid Chromatography/Quadrupole Time-Of-Flight (UHPLC/QTOF) system and identifications were confirmed by multiple mass spectrometry (MS/MS) analysis.

\section{Results}

Raboso Piave and Primitivo grape samples were collected in 2011 at full ripeness from the CRAVIT grapevine Germoplasma Collection (Susegana, Veneto, Italy). Berries were homogenized using liquid nitrogen and extracted with pure methanol. Identification of stilbenes was performed using the database GrapeMetabolomics expressly constructed with specific information available in the literature and other databases, such as their molecular formula and isotopic pattern [6]. Currently, this database contains around 1.000 putative metabolites of grape and wine. After a targeted search in GrapeMetabolomics, the raw data are processed by an untargeted algorithm and, if the search for resulting molecular formulae in other databases provides identification of a new compound, it is added to the database. As a consequence, by increasing the number of samples studied, GrapeMetabolomics can be expanded. Currently, more than $50 \mathrm{~V}$. vinifera grape varieties included in the Vigneto Project have been studied. By this approach, performing two analyses of a grape extract (positive and negative ionization mode) the molecular formulae of 320-450 metabolites are detected including polyphenols, anthocyanins, stilbene derivatives, flavones, flavanols, procyanindins, stilbenes, phenolic acids, glycoside aroma precursors.

In Raboso Piave grape extract about 80 antioxidant polyphenolic compounds were identified with score higher $95 \%$, among them 18 stilbene derivatives. Bioactive stilbenes identified in the two grape samples were: trans-resveratrol, $Z$ - and $E$-piceid, piceatannol and $Z$ - and $E$-astringin, and several resveratrol dimers, trimers and tetramers such as pallidol and pallidol-3-O-glucoside, $E$ - and $Z$ - $\varepsilon$-viniferin, $E$ - and
$Z$ - $\delta$-viniferin, caraphenol B, parthenocissin A, E- and $Z$-miyabenol C. Precursor ions at $m / z 679.197$ and the corresponding MS/MS fragments were assigned to trimers E- and Z-miyabenol C (previously found in V. vinifera leaves, [15]), and (+)-viniferol D (reported in $V$. vinifera stems, [20]); the precursor ions at $\mathrm{m} / \mathrm{z}$ 905.260 and their MS/MS fragments were assigned to tetramers hopheapenol (previously found in red wine, [10], and to ampelopsin $\mathrm{H}$, vaticanol $\mathrm{C}$-like or isohopeaphenol (found in V. vinifera leaves, [15]). In our knowledge, this is the first time that these resveratrol trimers and tetramers were found in grape. In general total content of stilbenes was $5 \mathrm{mg} / \mathrm{Kg}$ grape (for Raboso) and $10 \mathrm{mg} / \mathrm{Kg}$ grape (in Primitivo). Comparison between two samples showed similar trans-resveratrol content $(1.1 \mathrm{mg} / \mathrm{Kg})$, but Primitivo grape had higher dimers, trimers and tetramers, glucoside stilbenes and piceatannol content.

To our knowledge, this is the first time that such detailed qualitative and quantitative profiling of grape stilbene derivatives was reported. Although GrapeMetabolomics is not an open-source database and is specific for the enological field, this approach potentially can be applied to the metabolomics of other plant varieties.

\section{Acknowledgments}

VIGNETO Project (2011-20133), funded by MiPAAF, grant 11275/7303/11.

\section{References}

[1] Arapitsas P, Scholz M, Vrhovsek U, Di Blasi S, Biondi Bartolini A, Masuero D, Perenzoni D, Rigo A, Mattivi F. A metabolomic approach to the study of wine microoxygenation. PIoSoNE, 2012;7(5):e37783:1-11.

[2] Bavaresco L, Mattivi F, De Rosso M, Flamini R. Effects of Elicitors, Viticultural Factors, and Enological Practices on Resveratrol and Stilbenes in Grapevine and Wine. MiniReviews in Medicinal Chemistry. 2012;12:1366-81.

[3] Bertelli AA, Giovannini L, Giannessi D, Migliori M, Bernini W, Fregoni M, Bertelli A. Antiplatelet activity of synthetic and natural resveratrol in red wine. International Journal of Tissue Reactions. 1995;17:1-3.

[4] Cichewicz RH, Kouzi SA, Hamann MT. Dimerization of resveratrol by the grapevine pathogen Botrytis cinerea. Journal of Natural Products. 2000;63:29-33.

[5] Cuadros-Inostroza A, Giavalisco P, Hummel J, Eckardt A, Willmitzer L, Peña-Cortés H. Discrimination of wine attributes by metabolome analysis. Analytical Chemistry. 2010;82:357380. 
[6] Flamini R, De Rosso N, De Marchi F, Dalla Vedova A, Panighel A, Gardiman M, Maoz I, Bavaresco L. An innovative approach to grape metabolomics: Stilbene profiling by suspect screening analysis. Metabolomics 2013;(in press) (DOI: 10.1007/s11306-013-0530-0).

[7] Frankel EN, Waterhouse AL, Kinsella JE. Inhibition of human LDL oxidation by resveratrol. Lancet. 1993;341:1103-4.

[8] Frémont L, Belguendouz L, Delpal S. Antioxidant activity of resveratrol and alcohol-free wine polyphenols related to LDL oxidation and polyunsaturated fatty acids. Life Sciences. 1999;64:2511-21.

[9] Geahlen RL, McLaughlin JL. Piceatannol (3,4,3',5'tetrahydroxy-trans-stilbene) is a naturally occurring protein-tyrosine kinase inhibitor. Biochemical and Biophysical Research Communications. 1989;165:241-5.

[10] Guebailia HA, Chira K, Richard T, Mabrouk T, Furiga A, Vitrac X, Monti J-P, Delaunay J-C, Mérillon J-M. Hopeaphenol: The first resveratrol tetramer in wines from North Africa. Journal of Agricultural and Food Chemistry. 2006;54: 9559-64.

[11] Hung LM, Chen JK, Huang SS, Lee RS, Su MJ. Cardioprotective effect of resveratrol, a natural antioxidant derived from grapes. Cardiovascular Research. 2000;47:549-55.

[12] Jang M, Cai L, Udeani GO, Slowing KV, Thomas CF, Beecher $\mathrm{CW}$, Fong HH, Farnsworth NR, Kinghorn AD, Mehta RG, Moon RC, Pezzuto JM. Cancer chemopreventive activity of resveratrol, a natural product derived from grapes. Science. 1997;275:218-20.

[13] Krauss M, Singer H, Hollender J. LC-high resolution MS in environmental analysis: from target screening to the identification of unknowns. Analytical and Bioanalytical Chemistry. 2010;397:943-51.

[14] Larrosa M, Tomás-Barberán FA, Espín J-C. The grape and wine polyphenol piceatannol is a potent inducer of apoptosis in human SK-Mel-28 melanoma cells. European Journal of Nutrition. 2004;43:275-84.

[15] Mattivi F, Vrhovsek U, Malacarne G, Masuero D, Zulini L, Stefanini M, Moser C, Velasco R, Guella G. Profiling of resveratrol oligomers, important stress metabolites, accumulating in the leaves of hybrid Vitis vinifera (Merzling $\times$ Teroldego) genotypes infected with Plasmopara viticola. Journal of Agricultural and Food Chemistry. 2011;59:5364-75.

[16] Pace-Asciak CR, Hahn SE, Diamandis EP, Soleas G, Goldberg DM. The red wine phenolics trans-resveratrol and quercetin block human platelet aggregation and eicosanoid synthesis: implications for protection against coronary heart disease. Clinica Chimica Acta. 1995;235:207-19.

[17] Renaud S, de Lorgeril M. Wine, alcohol, platalets, and the French paradox for coronary heart disease. Lancet. 1992;339:1523-6

[18] Sbaghi M, Jeandet P, Bessis R, Leroux P. Degradation of stilbene-type phytoalexins in relation to the pathogenicity of Botrytis cinerea to grapevines. Plant Pathology. 1996;45: 139-44.

[19] Swanson-Mungerson M, Ikeda M, Lev L, Longnecker R, Portis T. Identification of latent membrane protein 2A (LMP2A) specific targets for treatment and eradication of Epstein-Barr virus (EBV)-associated diseases. Journal of Antimicrobial Chemotherapy. 2003;52:152-4.

[20] Takaya Y, Terashima K, Yan K-X, Niwa M. (+)-Viniferol D, a new stilbene trimer from the stem of Vitis vinifera 'Kyohou'. Heterocycles. 2003;60:1433-9.

[21] Vaclavik L, Lacina O, Hajslova J, Zweigenbaum J. The use of high performance liquid chromatography-quadrupole timeof-flight mass spectrometry coupled to advanced data mining and chemometric tools for discrimination and classification of red wines according to their variety. Analytica Chimica Acta. 2011;685:45-51. 